\title{
Desenvolvimento de um infiltrômetro de aspersão portátil ${ }^{1}$
}

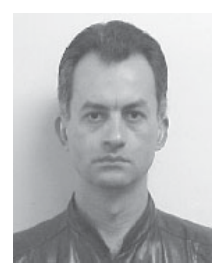

Teodorico Alves Sobrinho² ${ }^{2}$ Paulo A. Ferreira ${ }^{3}$ \& Fernando F. Pruski ${ }^{3}$

\footnotetext{
1 Parte da tese de doutorado apresentada pelo primeiro autor à UFV. Convênio UFMS/UFV/FAPEMIG

2 Universidade Federal de Mato Grosso do Sul. CP 533, Dourados, MS. E-mail: talves@ceud.ufms.br (Foto)

${ }^{3}$ DEA/UFV. Viçosa, MG
}

Protocolo $132-19 / 9 / 2001$

\begin{abstract}
Resumo: Desenvolveu-se, neste trabalho, um infiltrômetro de aspersão portátil, cujas características de precipitação relativas a diâmetro de gotas e energia cinética de impacto das gotas produzidas sobre solo, são semelhantes àquelas da chuva natural. Os resultados dos testes efetuados permitiram concluir-se que: o infiltrômetro desenvolvido permite aplicar-se água de forma não intermitente, numa área útil de $0,70 \mathrm{~m}^{2}$; a uniformidade de distribuição de água, expressa pelo coeficiente de uniformidade de Christiansen, apresentou valores entre 82 a $87 \%$; a relação entre a energia cinética da chuva produzida pelo infiltrômetro e a energia cinética da chuva natural, situou-se acima de $90 \%$ para intensidades de precipitação de até $100 \mathrm{~mm} \mathrm{~h}^{-1}$.
\end{abstract}

Palavras-chave: simulador de chuva, energia cinética, velocidade de infiltração

\section{Development of a portable sprinkler infiltrometer}

\begin{abstract}
A portable sprinkler infiltrometer with precipitation characteristics of drop diameter and kinetic energy of impact, similar to that of natural rainfall, was developed. Testing showed that the developed infiltrometer allowed continuous water application in an area of $0.70 \mathrm{~m}^{2}$ and the uniformity of water distribution, expressed by the Christiansen uniformity coefficient was between 82 and $87 \%$. The ratio between the kinetic energy of rainfall simulated by the infiltrometer and the kinetic energy of natural rainfall was more than $90 \%$ for precipitation intensities of up to $100 \mathrm{~mm} \mathrm{~h}^{-1}$.
\end{abstract}

Key words: rainfall simulator, kinetic energy, infiltration rate

\section{INTRODUÇÃO}

Em estudos hidrológicos concluiu-se que, nos países tropicais, a chuva é o tipo de precipitação mais importante, devido à sua capacidade em produzir erosão do solo conseqüente ao impacto das gotas no solo e ao escoamento superficial. A resposta do solo à chuva é fundamental para a escolha do sistema adequado de manejo de solo e água, com vistas à manutenção da capacidade produtiva deste solo, o que envolve, necessariamente, o conhecimento sobre os processos de infiltração, escoamento superficial da água e erosão do solo.

No delineamento e dimensionamento de projetos hidroagrícolas, como drenagem de superfície, irrigação por aspersão e engenharia de conservação de solo e água, os valores da velocidade de infiltração da água no solo são fundamentais e devem ser determinados, preferencialmente, sob condições de precipitação.

Os equipamentos utilizados para determinação da velocidade de infiltração de água no solo, são denominados infiltrômetros e são de dois tipos: a) infiltrômetros com aplicação de água por inundação, ou simplesmente infilttrômetros; e b) infiltrômetros com aplicação da água por aspersão ou simuladores de chuva (Pinto et al., 1976). Dentre os tipos de equipamentos citados, o comumente utilizado é o infiltrômetro de anel, não apenas por ser o mais simples como, também, pelo seu fácil manuseio no campo; entretanto, sua eficiência depende de uma série de fatores que, por sua vez, dependem de como são manuseados no campo. É constituído por dois anéis concêntricos medindo $300 \mathrm{~mm}$ de altura e diâmetro de 250 e $500 \mathrm{~mm}$, respectivamente.

A velocidade de infiltração é uma característica importante na calibração de modelos matemáticos empregados no planejamento e manejo de sistemas de irrigação e conservação de solo e água e seu valor apresenta grande dependência do método utilizado na determinação. Sidiras \& Roth (1987) e Brito et al. (1996) mostraram que os valores da velocidade de infiltração determinados por meio de infiltrômetro de anel são maiores que os valores obtidos pela aplicação de água por aspersão. 
Vem sendo enfatizada, pelos pesquisadores da área de engenharia de conservação de solo e água, a utilização de infiltrômetros de aspersão ou simuladores de chuva, que permitem controlar as características relativas à intensidade, duração e freqüência da precipitação; no entanto, para que um simulador de chuvas seja considerado satisfatório, é necessário que ele: a) apresente relação entre a energia cinética da precipitação simulada e aquela da chuva natural acima de $75 \%$ (Meyer \& Mccune, 1958); b) aplique água de modo contínuo na parcela experimental ou, no mínimo, execute duas aplicações por segundo compondo, assim, uma aplicação não intermitente (Morin et al., 1967); c) permita o uso de parcela experimental com área superior a $0,50 \mathrm{~m}^{2}$, caracterizada como parcela alvo de precipitação, pois experimentos cuja área útil é inferior a 0,50 $\mathrm{m}^{2}$, estão sujeitos a resultados tendenciosos (Smith, 1976).

Morin et al. (1967) classificam os simuladores de chuva em dois tipos: a) simuladores equipados com gotejadores e b) simuladores equipados com bicos. Os simuladores equipados com bicos têm menor custo de construção e, para a formação de gotas, eles devem ser operados sob determinada pressão, a qual pode ser ajustada para obtenção de uma velocidade de impacto das gotas no solo, similar à velocidade terminal das gotas de chuva. Assim, os bicos podem ser posicionados a uma altura inferior a $3 \mathrm{~m}$ em relação ao solo, o que facilitará o uso do equipamento no campo.

Diversos tipos de simuladores de chuva desenvolvidos são destinados principalmente aos estudos sobre a erosão do solo. Em outras aplicações de interesse, como no caso da determinação da velocidade de infiltração da água no solo, em que são necessárias diversas determinações no campo, os equipamentos utilizados em estudos relativos à erosão tornamse limitados devido, principalmente, às suas dimensões. Simuladores de pequenas dimensões, como os desenvolvidos por Shelton et al. (1985) e Tossel et al. (1990) apesar de possibilitarem alta uniformidade de aplicação, apresentam valores de energia cinética das gotas de chuva simulada muito inferiores aos da chuva natural, sendo inadequados, portanto, para determinação da velocidade de infiltração.

Em estudos sobre infiltração de água no solo realizados por Silveira \& Chevallier (1991) e sobre a erodibilidade do solo, realizados por Bajracharya et al. (1992) e Ghidey \& Alberts (1994) vêm sendo utilizados os simuladores com dispositivo pendular, semelhantes àquele descrito e utilizado por Meyer \& Harmon (1979) em parcelas experimentais medindo de 0,3 a 1,0 $\mathrm{m}^{2}$. Esses simuladores apresentam alta intermitência de aplicação de água, notadamente para valores de intensidade de precipitação inferiores a $70 \mathrm{~mm} \mathrm{~h}^{-1}$, além de construção complexa e difícil operacionalidade no campo, em razão de suas dimensões.

Assim, o presente trabalho teve por objetivo desenvolver um simulador de chuvas portátil com características construtivas e operacionais simples, capaz de simular chuvas com intensidade controlável e alta uniformidade de distribuição e que apresente relação adequada entre energia cinética da chuva simulada e da chuva natural.

\section{MATERIAL E MÉTODOS}

Considerando-se os critérios para o projeto de um simulador de chuvas, enumerados por Meyer \& Harmon (1979) e Tossel et al. (1987) propôs-se que o equipamento atenda aos seguintes requisitos: a) produza gotas de diâmetro médio similar ao da chuva natural; b) aplique água numa parcela com área útil medindo de 0,50 a $1,0 \mathrm{~m}^{2}$, com coeficiente de uniformidade de Christiansen superior a $80 \%$; c) que apresente valores da relação entre a energia cinética da chuva produzida pelo infiltrômetro e aquela da chuva natural superior a $75 \%$; d) enfim, que simule chuvas sobre a parcela em estudo, de modo não intermitente.

Inicialmente, para o desenvolvimento do infiltrômetro selecionaram-se e se caracterizaram os bicos a serem utilizados para aplicação de água, de forma que atendessem ao critério relativo à produção de gotas de diâmetro médio similar ao da chuva natural, definido para o projeto do equipamento. Para a obtenção do diâmetro volumétrico médio das gotas, uniformidade de distribuição e intensidade de aplicação de água, desenvolveram-se testes no Laboratório de Hidráulica do Departamento de Engenharia Agrícola da Universidade Federal de Viçosa, onde foi construída uma bancada de testes para os bicos (Alves Sobrinho, 1997).

Conforme Eigel \& Moore (1983) o método da farinha foi empregado para determinar o diâmetro volumétrico médio das gotas. Os testes foram realizados com os bicos posicionados a $2,0 \mathrm{~m}$ de altura e submetidos às pressões de 14,2, 28,4 e 35,6 $\mathrm{kPa}$. A pressão foi medida a $0,10 \mathrm{~m}$ da saída do bocal, utilizando-se um manômetro antivibrante, com saída angular.

A uniformidade de distribuição de água dos bicos foi calculada empregando-se o coeficiente de uniformidade proposto por Christiansen (1942). Para a obtenção do volume de água aplicada, utilizaram-se 25 copos-coletores, medindo $81 \mathrm{~mm}$ de diâmetro e $110 \mathrm{~mm}$ de altura, distribuídos numa área de $1,0 \mathrm{~m}^{2}(1,0 \times 1,0 \mathrm{~m})$. Determinou-se a massa dos volumes de água dos copos-coletores, com balança digital de precisão 0,01 g. Os bicos foram posicionados a 2,0 $\mathrm{m}$ de altura e submetidos à pressão de $35,6 \mathrm{kPa}$. O tempo de aplicação de água foi dois minutos, com três repetições por teste. A intensidade média de precipitação de água, para cada teste, foi determinada pela relação entre a lâmina média de água obtida nos coletores e o tempo de aplicação.

Utilizando-se dados do perfil de distribuição de água dos bicos selecionados e empregando-se recursos computacionais de uma planilha eletrônica de cálculo, simularam-se superposições das precipitações para diversas combinações de altura de aplicação, espaçamentos e posição relativa entre dois, três e quatro bicos. A área útil de aplicação foi determinada pela combinação de espaçamento e posição entre dois bicos que apresentaram melhor coeficiente de uniformidade na aplicação de água.

A energia de impacto sobre o solo da precipitação simulada pelos bicos foi estimada por meio da Eq. 1, proposta por Stillmunkes \& James (1982). 


$$
\mathrm{E}_{\mathrm{c} / \mathrm{a}}=\frac{10^{-3}}{2} \rho_{\mathrm{w}} \mathrm{Lv}^{2}
$$

em que:

$\mathrm{E}_{\mathrm{c} / \mathrm{a}}$ - energia cinética por unidade de área, $\mathrm{J} \mathrm{m}^{-2}$

$\rho_{\mathrm{w}} \quad$ - massa específica da água, $\mathrm{kg} \mathrm{m}^{-3}$

L - lâmina de água média aplicada pelos bicos, $\mathrm{mm}$

$\mathrm{v} \quad$ - velocidade da gota, $\mathrm{m} \mathrm{s}^{-1}$

A velocidade das gotas foi estimada utilizando-se a Eq. 2, equação do movimento, descrita por Li \& Kawano (1995) e Stillmunkes \& James (1982).

$$
\frac{\mathrm{d} v}{\mathrm{dt}}=\mathrm{g}-\mathrm{C}_{2} \mathrm{v}^{2}
$$

em que:

$$
\begin{array}{ll}
\mathrm{g} & \text { - aceleração da gravidade, } \mathrm{m} \mathrm{s}^{-2} \\
\mathrm{C}_{2} & \text { - coeficiente de arraste } \\
\mathrm{t} & \text { - tempo, } \mathrm{s}
\end{array}
$$

A solução da Eq. 2 foi obtida empregando-se o método numérico de Runge-Kutta, de quarta ordem. Para aplicação desse método, assumiu-se que a velocidade inicial da gota é igual à velocidade inicial do jato de água ao deixar o bico, conforme recomendam Li \& Kawano (1995) enquanto a energia cinética da chuva natural foi estimada através da Eq. 3, desenvolvida por Wischmeier \& Smith (1958) e expressa na forma:

$$
\mathrm{EcN}=(17,124+5,229 \log \mathrm{I}) \mathrm{It}
$$

em que:

EcN - energia cinética da chuva natural por unidade de área, $\mathrm{J} \mathrm{m}^{-2}$

I - intensidade média de precipitação do bico, $\mathrm{mm} \mathrm{h}^{-1}$

t $\quad$ - tempo de precipitação, $h$

$\mathrm{Na}$ bancada de testes foram desenvolvidos e avaliados quatro dispositivos para regular a intensidade de precipitação dos bicos, além de selecionado o que melhor se adaptou ao controle da intensidade de precipitação e proporcionou melhor uniformidade de distribuição de água na área útil de aplicação. Selecionados os bicos e desenvolvido o dispositivo regulador da intensidade de precipitação, passou-se ao projeto da estrutura de suporte dos bicos e do regulador de intensidade de precipitação. O simulador foi construído em módulos, utilizando-se perfis metálicos, tubos e chapas de aço galvanizados, motor elétrico de $368 \mathrm{~W}$, redutor de velocidades e um conjunto motobomba de $368 \mathrm{~W}$ de potência. Avaliou-se o equipamento desenvolvido comparando-se os valores obtidos para diâmetro volumétrico médio de gotas, uniformidade de distribuição de água, intensidade de precipitação e energia cinética da precipitação produzida pelo equipamento, com os valores previamente definidos para o seu desenvolvimento.
Para se determinar a velocidade das gotas da chuva simulada pelos bicos e a energia cinética das chuvas simulada e natural, utilizou-se um programa computacional desenvolvido por Alves Sobrinho (1997).

\section{RESULTADOS E DISCUSSÃO}

Após a avaliação preliminar de diversos tipos e modelos de bico, selecionaram-se os modelos de bico especificados como Veejet $80.70 ; 80.100$ e 80.150. Os valores dos diâmetros médios das gotas, obtidos para o bico modelo Veejet 80.70, variaram entre 1,5 e $1,8 \mathrm{~mm}$ e, para os bicos Veejet 80.100 e 80.150 , os diâmetros médios variaram de 1,8 a 3,0 mm, conforme a pressão de serviço.

Comparando-se os diâmetros médios de gotas do bico Veejet 80.70 e $80.100 \mathrm{com}$ os dados de chuva natural apresentados por Laws \& Parsons (1943) verificou-se que o primeiro pode ser recomendado apenas para chuvas com intensidades de precipitação de até $8 \mathrm{~mm} \mathrm{~h}^{-1}$, limite este inferior àqueles desejados para o infiltrômetro em estudo. O bico Veejet 80.100 produz gotas com diâmetro médio semelhante àquele das gotas de chuva natural, para intensidade entre 18 e $128 \mathrm{~mm} \mathrm{~h}^{-1}$, conforme a pressão de serviço utilizada. A velocidade de impacto das gotas atingiu o valor máximo de $7,2 \mathrm{~m} \mathrm{~s}^{-1}$, correspondente à velocidade de chuvas naturais com intensidade em torno de $40 \mathrm{~mm} \mathrm{~h}^{-1}$. Para esta intensidade de precipitação, o diâmetro médio das gotas da chuva natural é de $2,42 \mathrm{~mm}$. Os resultados relativos ao diâmetro médio de gotas e velocidade de impacto no solo, obtidos com o bico Veejet 80.100, mostraram que esse bico poderá ser utilizado para simular precipitações com intensidade de até $40 \mathrm{~mm} \mathrm{~h}^{-1}$ e, para intensidade de precipitação superior a $40 \mathrm{~mm} \mathrm{~h}^{-1}$, deve-se utilizar o bico Veejet 80.150.

De acordo com os resultados obtidos nos testes individuais dos bicos, observou-se que, com a utilização de apenas um bico, não era possível aplicar-se água em parcela com área útil superior a $0,50 \mathrm{~m}^{2}$ e coeficiente de uniformidade de Christiansen superior a $80 \%$. Os resultados da precipitação produzida pelos bicos Veejet 80.100 , relativos ao diâmetro médio das gotas e velocidade de impacto das gotas no solo, aproximaram-se satisfatoriamente dos valores de diâmetro de gotas e velocidade de impacto da chuva natural, para determinadas faixas de valores de intensidade de precipitação.

A superposição de precipitações, empregando dois bicos, aumentou a uniformidade de distribuição de água e a área útil de aplicação, considerando-se a faixa central como a área útil de precipitação, que foi possível graças ao tipo de perfil de distribuição proporcionado pelos bicos.

$\mathrm{Na}$ Tabela 1 encontram-se os valores do coeficiente de uniformidade, a intensidade de precipitação e as áreas de aplicação de água consideradas, obtidos a partir de superposições dos perfis de precipitação, para quatro combinações de espaçamento e posição dos bicos. A posição paralela dos bicos indica que a superposição foi realizada com os jatos de aplicação de água em paralelo e os bicos dispostos diametralmente. Por outro lado, uma posição defasada dos bicos significa que 
Tabela 1. Coeficiente de uniformidade (CUC), intensidade de aplicação (I) e áreas úteis de aplicação de água obtidos com a superposição de precipitações

\begin{tabular}{|c|c|c|c|c|c|c|}
\hline \multirow[b]{2}{*}{ Espaçamento e Posição dos Bicos } & \multicolumn{3}{|c|}{ Bicos Veejet 80.100} & \multicolumn{3}{|c|}{ Bicos Veejet 80.150} \\
\hline & $\begin{array}{c}\text { CUC } \\
(\%)\end{array}$ & $\begin{array}{c}\mathrm{I} \\
\left(\mathrm{mm} \mathrm{h}^{-1}\right)\end{array}$ & $\begin{array}{l}\text { Área } \\
\left(\mathrm{m}^{2}\right)\end{array}$ & $\begin{array}{c}\text { CUC } \\
(\%)\end{array}$ & $\begin{array}{c}\mathrm{I} \\
\left(\mathrm{mm} \mathrm{h}^{-1}\right)\end{array}$ & $\begin{array}{l}\text { Área } \\
\left(\mathrm{m}^{2}\right)\end{array}$ \\
\hline $400 \mathrm{~mm}$ e bicos paralelos & 84 & 1.503 & 0,70 & 83 & 2.213 & 0,77 \\
\hline $500 \mathrm{~mm}$ e bicos paralelos & 83 & 1.402 & 0,56 & 81 & 1.941 & 0,88 \\
\hline $400 \mathrm{~mm}$ e defasados de $200 \mathrm{~mm}$ & 88 & 1.575 & 0,49 & - & - & - \\
\hline $500 \mathrm{~mm}$ e defasados de $100 \mathrm{~mm}$ & 84 & 1.438 & 0,48 & - & - & - \\
\hline
\end{tabular}

os jatos de aplicação de água são paralelos e os bicos não estão posicionados de maneira diametralmente oposta. Analisando-se esta tabela, observa-se que os bicos Veejet 80.100 e 80.150 , paralelos e com espaçamento de $400 \mathrm{~mm}$, forneceram melhor combinação para espaçamento e posição dos bicos em áreas úteis de 0,70 e $0,77 \mathrm{~m}^{2}$. Para os quatro espaçamentos e posições dos bicos apresentados, o coeficiente de uniformidade variou de 81 a $84 \%$ para os dois modelos de bico avaliados. À medida que aumentava o espaçamento entre os bicos, para determinada área útil, ocorria redução no valor do coeficiente de uniformidade devido ao perfil de precipitação apresentado pelo bico. Desta forma, a delimitação da área útil de aplicação era associada ao coeficiente de uniformidade.

Os resultados indicaram que o uso de dois bicos espaçados $400 \mathrm{~mm}$ e posicionados diametralmente, preenchem os critérios referentes à área mínima de aplicação e uniformidade mínima de distribuição de água na parcela experimental; no entanto, evidenciava a necessidade do desenvolvimento de dispositivos que permitam a redução da intensidade de precipitação, de forma significativa.

O dispositivo regulador desenvolvido foi denominado obturador rotativo ajustável (Fig. 1). Para reduzir a intensidade de precipitação dos bicos selecionados e, simultaneamente, garantir a intermitência mínima tolerada no projeto do simulador, o mesmo tinha que ser operado de forma rotativa. $\mathrm{O}$ obturador se constitui no sistema de controle da intensidade de precipitação, com oito fendas radiais de aberturas ajustáveis entre zero e $25 \mathrm{~mm}$. O número e abertura das fendas determinam a intensidade de precipitação sobre a área experimental. Ajustando-se as oito fendas radiais na abertura máxima, o obturador rotativo proporcionou a obtenção de intensidades de precipitação de até $308 \mathrm{~mm} \mathrm{~h}^{-1}$, com uniformidade de distribuição superior a $80 \%$. Utilizando-se no mínimo duas fendas diametralmente opostas e velocidade angular de 56 rotações min $^{-1}$, obtém-se precipitações praticamente contínuas pois, segundo Morin et al. (1967) quando ocorre freqüência de duas aplicações por segundo, a precipitação pode ser considerada não intermitente.

Visando-se à utilização de dois bicos paralelos e posicionados a $400 \mathrm{~mm}$, construiu-se um interceptor de água, conforme esquematizado nas Figuras 2 e 3. Além de receber o excesso de água captado pelas calhas, impedindo que esse excesso caísse na área útil da parcela experimental, o interceptor tem também, como função, eliminar os picos de precipitação que ocorrem nas extremidades do jato de água formado pelo bico. Na Tabela
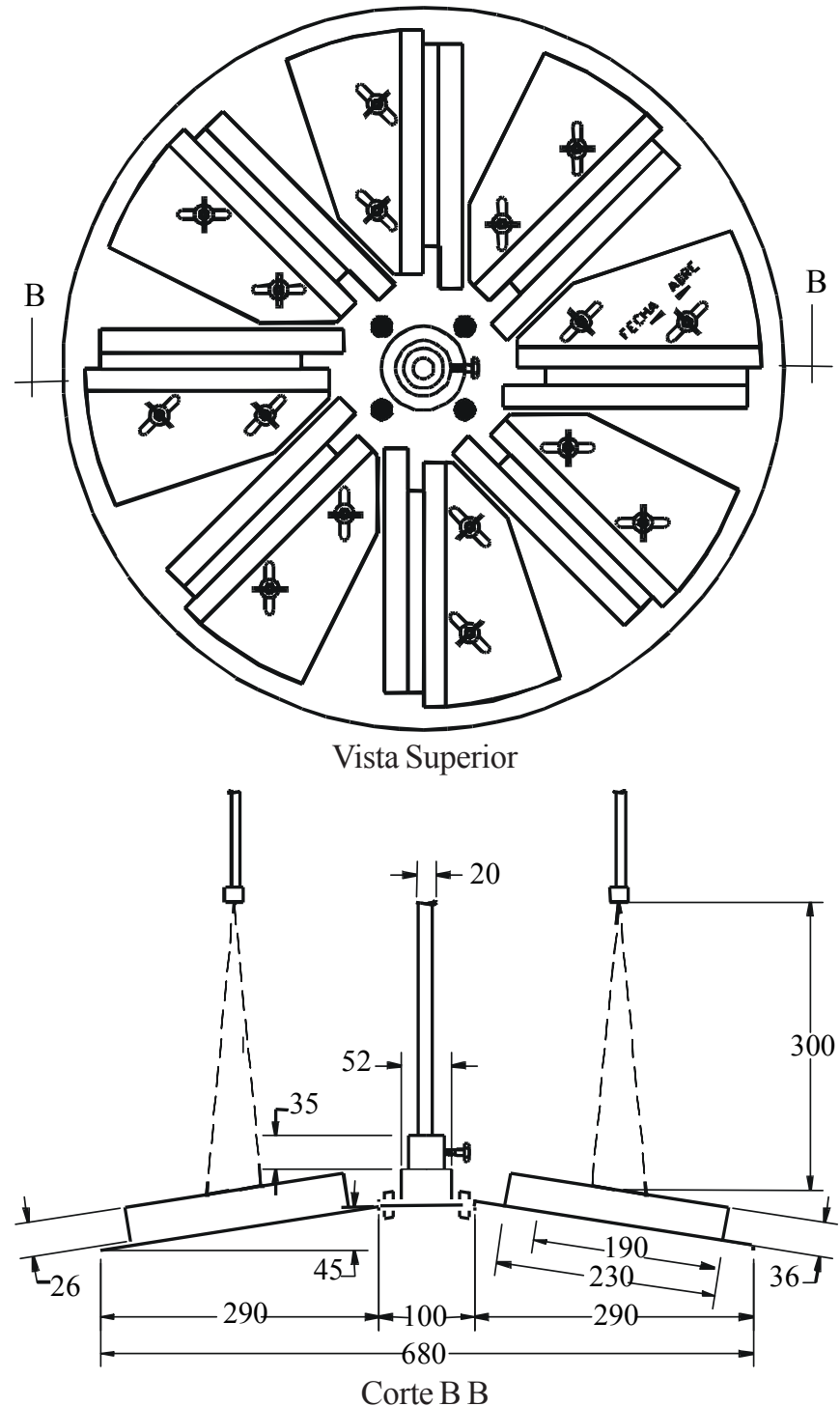

Figura 1. Obturador rotativo ajustável (dimensões em mm)

2 encontram-se os valores de intensidade de precipitação e coeficiente de uniformidade obtidos a partir de combinações do número de fendas abertas e da abertura de cada fenda do obturador, com o uso do interceptor construído. O coeficiente de uniformidade variou entre 82 e $87 \%$, ficando dentro da faixa de valores desejáveis.

O infiltrômetro foi construído em seis módulos, conforme descritos a seguir:

a) estrutura de sustentação com sistema telescópico, de modo a permitir o ajuste da altura de aplicação de água e o nivelamento do equipamento, Figuras 4 e 5 ; 


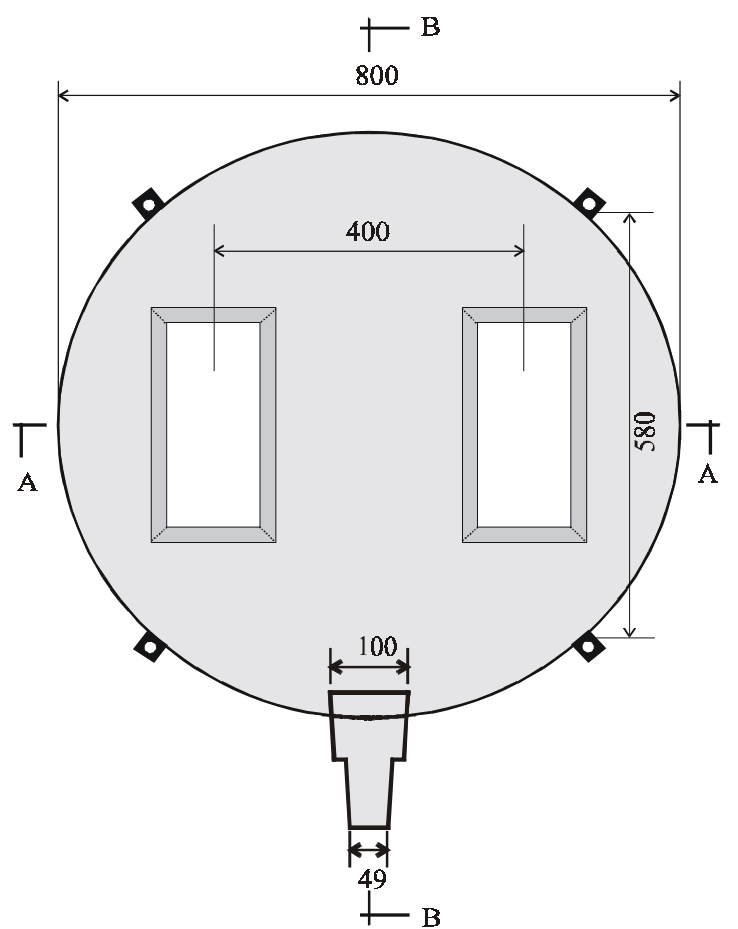

Figura 2. Vista superior do interceptor de água (dimensões emmm)

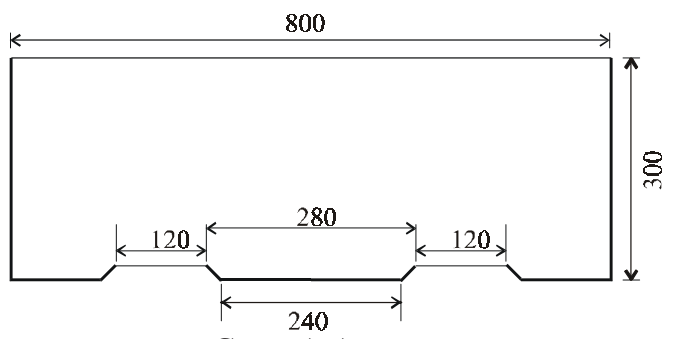

Corte A A

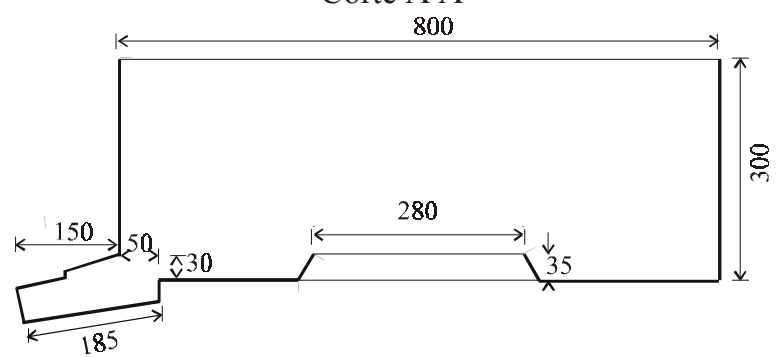

Corte B B

Figura 3. Cortes AA e BB no interceptor de água (dimensões emmm)
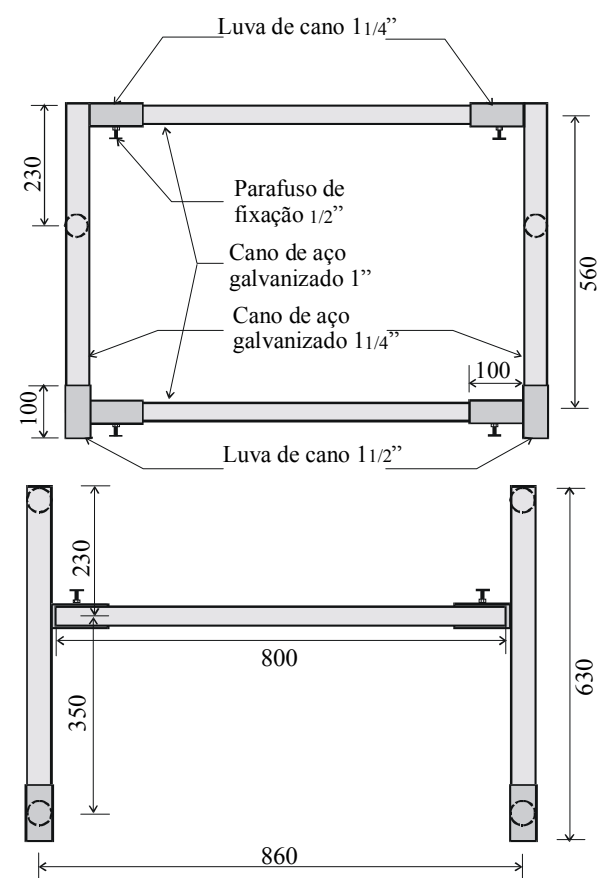

Figura 4. Perfis da parte superior da estrutura do infiltrômetro (dimensões em mm)

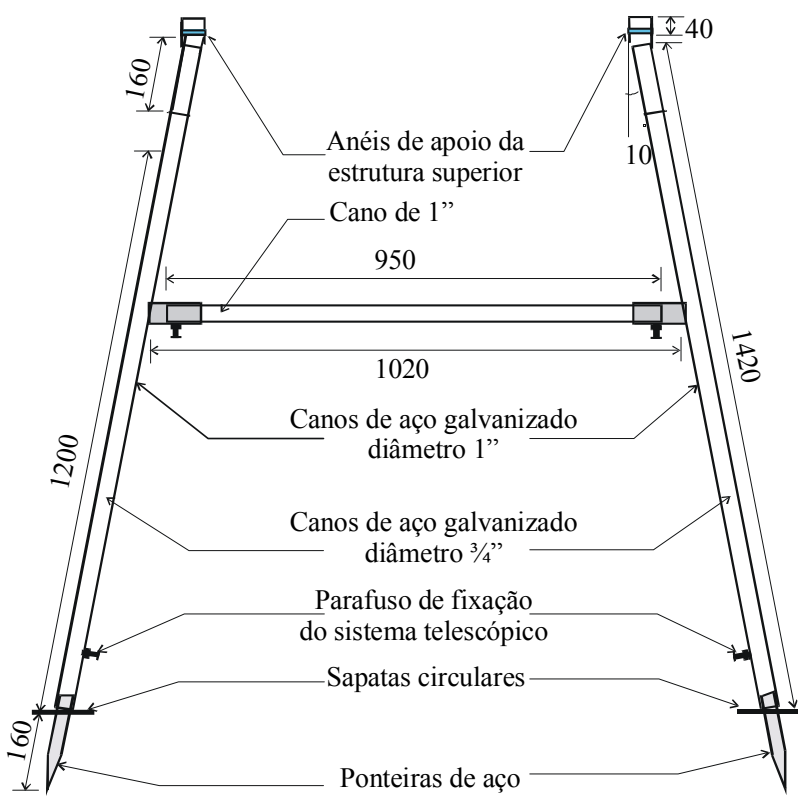

Figura 5. Perfis da parte inferior da estrutura do infiltrômetro (dimensões em mm)

Tabela 2. Coeficiente de uniformidade (CUC) e intensidade de aplicação de água (I) obtidos a partir de combinações do número e abertura de fenda do obturador desenvolvido

\begin{tabular}{|c|c|c|c|c|c|c|c|}
\hline \multicolumn{2}{|c|}{ Ajuste no Obturador } & \multirow{2}{*}{\multicolumn{2}{|c|}{$\begin{array}{l}\text { Bicos Veejet } 80.100 \\
\text { (Pressão: } 32,7 \mathrm{kPa} \text { ) }\end{array}$}} & \multicolumn{2}{|c|}{ Ajuste no Obturador } & \multirow{2}{*}{\multicolumn{2}{|c|}{$\begin{array}{c}\text { Bicos Veejet } 80.150 \\
\text { (Pressão: } 27,6 \mathrm{kPa} \text { ) }\end{array}$}} \\
\hline \multirow{2}{*}{$\begin{array}{c}\text { Número de } \\
\text { Fendas Abertas }\end{array}$} & \multirow{2}{*}{$\begin{array}{l}\text { Abertura da } \\
\text { Fenda }(\mathrm{mm})\end{array}$} & & & \multirow{2}{*}{$\begin{array}{c}\text { Número de } \\
\text { Fendas Abertas }\end{array}$} & \multirow{2}{*}{$\begin{array}{l}\text { Abertura da } \\
\text { Fenda }(\mathrm{mm})\end{array}$} & & \\
\hline & & $\mathrm{I}\left(\mathrm{mm} \mathrm{h}^{-1}\right)$ & CUC (\%) & & & $\mathrm{I}\left(\mathrm{mm} \mathrm{h}^{-1}\right)$ & CUC $(\%)$ \\
\hline 2 & 10 & 19,4 & 85,5 & 2 & 15 & 49,7 & 82,0 \\
\hline 2 & 15 & 25,7 & 85,8 & 2 & 20 & 65,0 & 83,0 \\
\hline 2 & 20 & 35,9 & 84,6 & 4 & 15 & 95,6 & 83,7 \\
\hline 2 & 25 & 45,8 & 83,3 & 4 & 20 & 131,1 & 84,5 \\
\hline 4 & 15 & 54,5 & 84,3 & 6 & 15 & 143,0 & 84,7 \\
\hline 4 & 20 & 69,9 & 84,9 & 6 & 20 & 180,5 & 85,3 \\
\hline 6 & 15 & 80,5 & 84,7 & 6 & 25 & 227,5 & 86,1 \\
\hline 6 & 20 & 102,1 & 85,0 & 8 & 25 & 307,8 & 87,1 \\
\hline
\end{tabular}


b) sistema de acionamento do obturador rotativo, Figura 6 , composto por um motor elétrico, monofásico, de $372 \mathrm{~W}$ a 1720 rotações min $^{-1}$ e redutor de velocidade, com duas polias de $150 \mathrm{~mm}$ de diâmetro, montado sobre perfil metálico em "U" $(100 \times 50 \mathrm{~mm})$;

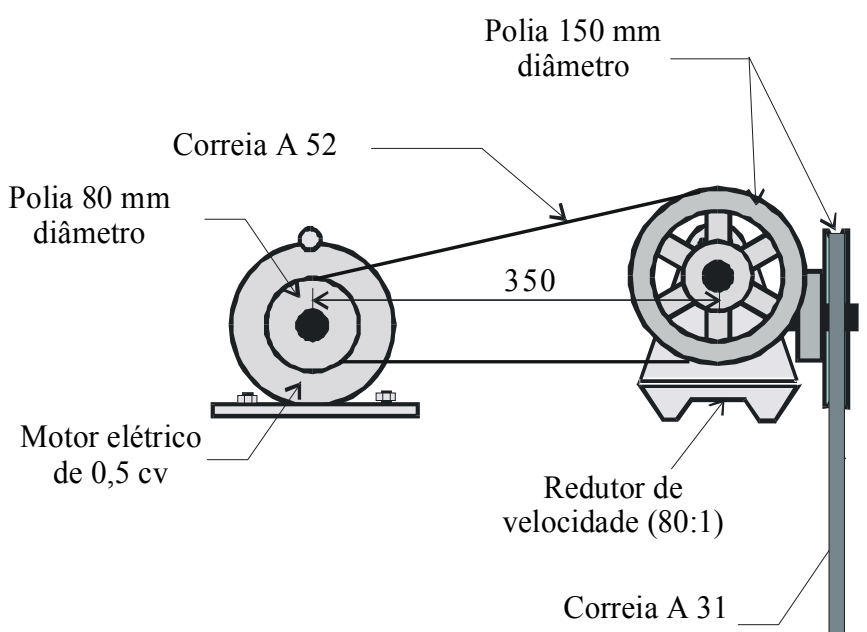

Figura 6. Sistema de acionamento do obturador rotativo (dimensões em mm)

c) mecanismo de transmissão de potência, Figura 7, composto por polia de $50 \mathrm{~mm}$ de diâmetro, correia em V, tamanho A31, dois mancais para fixação do eixo de transmissão de potência e um conjunto de duas engrenagens de 25 e 40 dentes, constituindo um sistema coroa e pinhão;

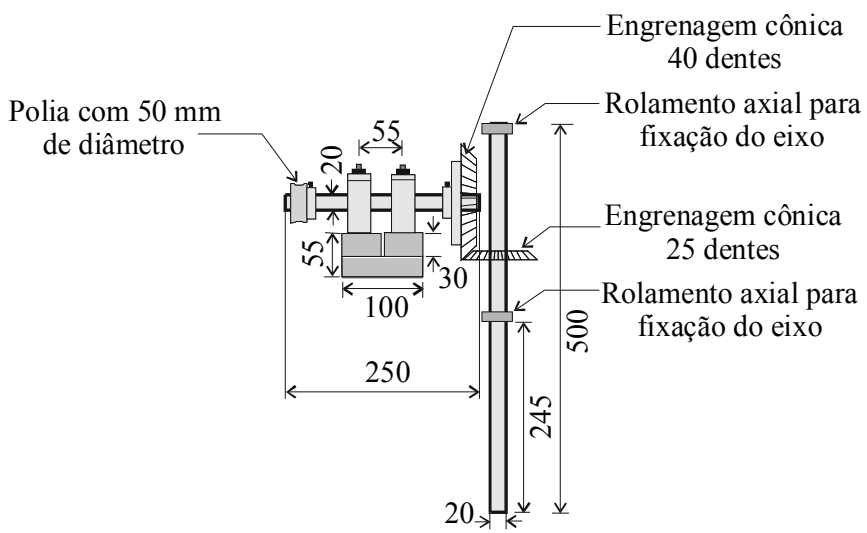

Figura 7. Mecanismo de transmissão do obturador rotativo (dimensões em mm)

d) sistema de aplicação de água, Figura 8, construído em tubos de cobre de 22 e $15 \mathrm{~mm}$ de diâmetro, equipado com manômetro antivibrante de saída angular, montado sobre perfil metálico em "U" (100 x $50 \mathrm{~mm})$ e braçadeiras, para permitir o ajuste da altura de aplicação de água;

e) sistema regulador da intensidade de precipitação, composto pelos dispositivos obturador e interceptor de água, construídos em chapas de aço galvanizado números 22 e 24 , respectivamente;

f) sistema de bombeamento de água, composto por motobomba de $372 \mathrm{~W}(0,5 \mathrm{cv})$, tubos de sucção e recalque de

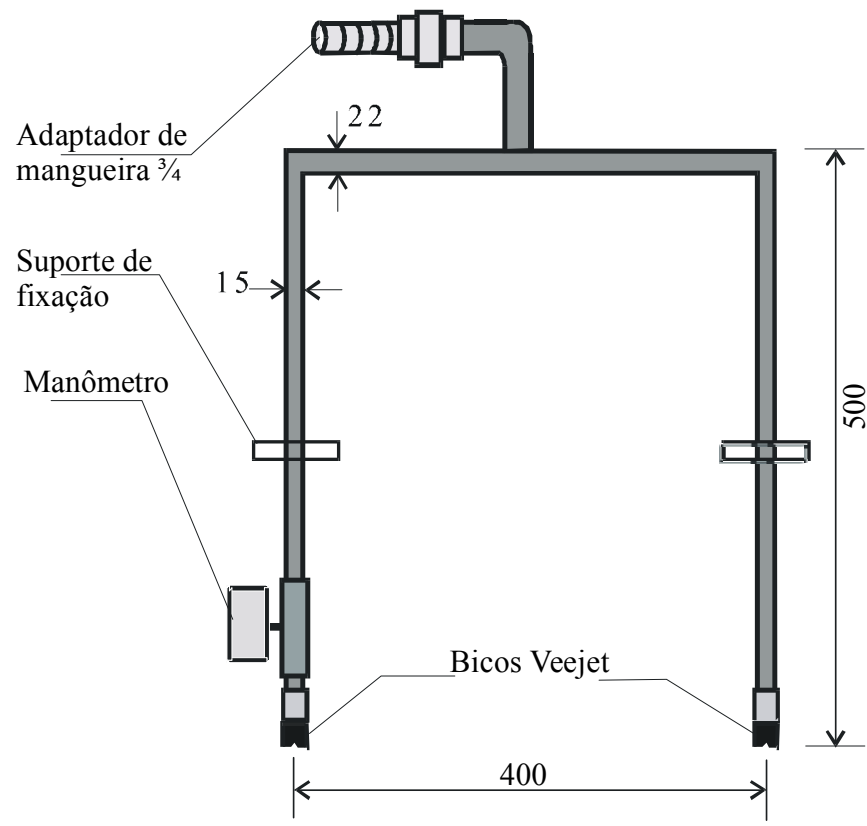

Figura 8. Sistema de aplicação de água (dimensões em mm)

25,40 e 19,05 mm de diâmetro, respectivamente, registro de gaveta de 19,05 mm para regular a vazão de água para os bicos e reservatório com capacidade para 200 litros de água. A estrutura de sustentação desse sistema foi construída em perfis metálicos em forma de "L" (30 x 30 mm).

O equipamento foi construído de modo que sua montagem e desmontagem no campo sejam efetuadas por duas pessoas. O perfil frontal do infiltrômetro, mostrando o sistema de acionamento, o mecanismo de transmissão, o obturador rotativo ajustável, o interceptor de água, o sistema de aplicação de água e a estrutura do equipamento, é mostrado na Figura 9.

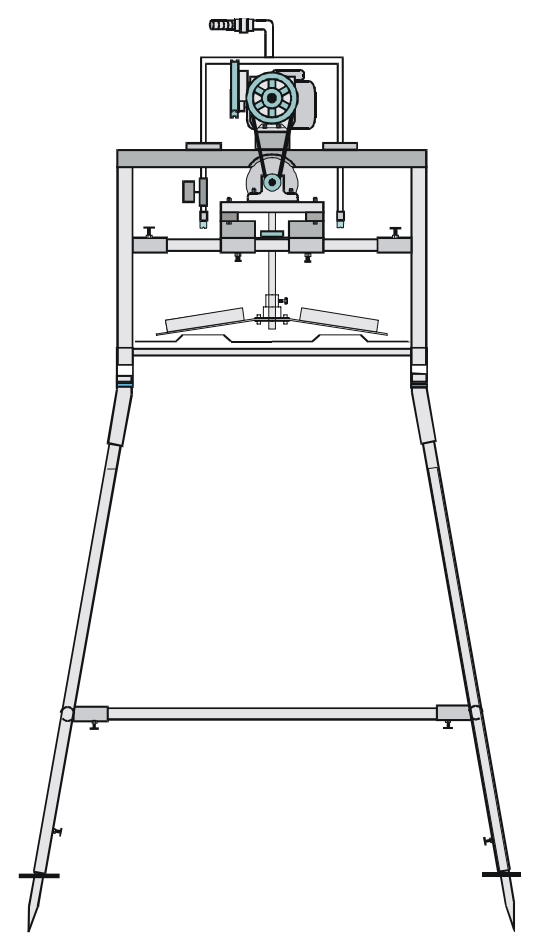

Figura 9. Perfil frontal do infiltrômetro desenvolvido 
A energia necessária para acionar os motores elétricos dos sistemas de acionamento e bombeamento, é fornecida por um conjunto motogerador portátil, com potência nominal de 2500 $\mathrm{W}, 220$ volts e motor de quatro tempos, a gasolina.

O infiltrômetro desenvolvido possibilita a determinação do escoamento superficial numa parcela experimental de $0,70 \mathrm{~m}^{2}$, com a utilização de dois bicos Veejet 80.100 ou 80.150 , posicionados a $400 \mathrm{~mm}$.

Deve-se montar as partes inferior e superior da estrutura, separadamente. A seguir, montar, na parte superior, o mecanismo de transmissão e acoplar esta parte à parte inferior da estrutura do infiltrômetro; posteriormente, então, montar os sistemas reguladores de intensidade de aplicação (interceptor de água e obturador rotativo), acionamento e aplicação de água.

Ao montar o infiltrômetro no campo, deve-se: a) nivelar e posicionar a parte inferior do interceptor de água a $1,95 \mathrm{~m}$ de altura, em relação ao solo; b) posicionar os bicos na altura de 2,30 m em relação ao solo e a $0,30 \mathrm{~m}$ em relação ao obturador rotativo e centralizados em relação à área útil de precipitação de $0,70 \mathrm{~m}^{2}$; c) usar bicos modelos Veejet 80.100 , na pressão de $32,7 \mathrm{kPa}$, para intensidade de precipitação entre 20 e $40 \mathrm{~mm} \mathrm{~h}^{-1}$ e Veejet 80.150 , na pressão de $35,6 \mathrm{kPa}$, para intensidades de precipitação entre 40 e $300 \mathrm{~mm} \mathrm{~h}^{-1}$ e d) afixar uma lona em torno da estrutura inferior do equipamento.

A área da parcela experimental deverá ser contornada por um dispositivo de formato retangular, construído de chapas de aço galvanizado número 22, para permitir a determinação do volume de água escoado superficialmente, conforme Figura 10. A relação entre o volume de água escoado e a área da parcela experimental, corresponde à lâmina de escoamento superficial. A diferença entre a lâmina de água aplicada e a lâmina escoada superficialmente, representa a lâmina de água infiltrada.
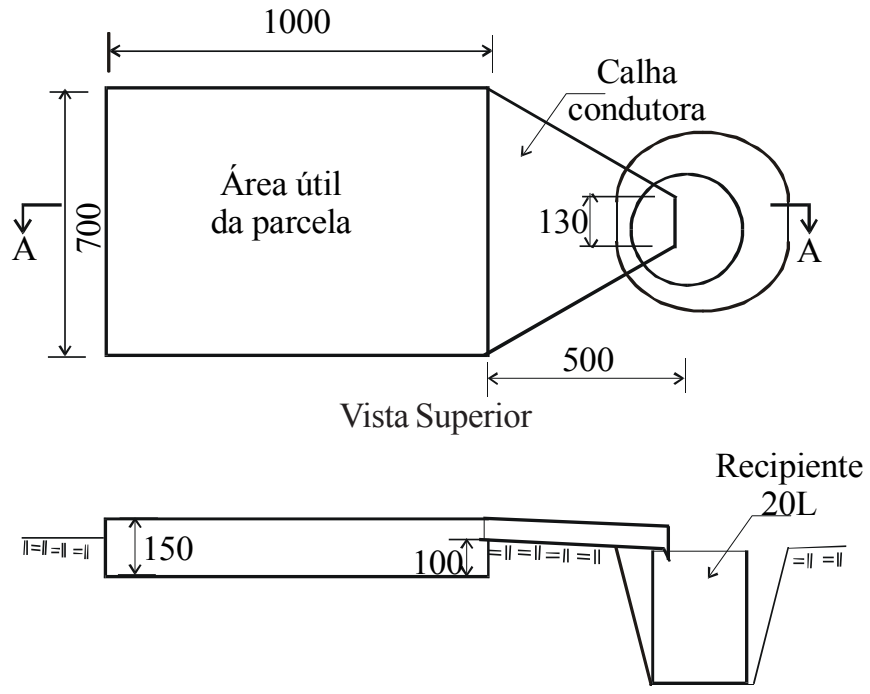

Corte A A

Figura 10. Dispositivo para determinar o volume de escoamento superficial

A relação entre a energia cinética da chuva produzida pelo infiltrômetro (EcSimulada) e a energia cinética da chuva natural $(\mathrm{EcN})$ em função da intensidade de precipitação (Ip), conforme apresentada na Figura 11, correspondeu a valores acima de
$90 \%$ para intensidades de precipitação até 40 e $100 \mathrm{~mm} \mathrm{~h}^{-1}$, para os bicos Veejet 80.100 e 80.150 , respectivamente. Os valores da relação entre a energia cinética da precipitação produzida pelo infiltrômetro provido com bicos Veejet 80.150 e a energia cinética da chuva natural, para intensidade de precipitação de até 100 $\mathrm{mm} \mathrm{h}^{-1}$, foram semelhantes aos obtidos por Meyer \& Harmon (1979) utilizando um simulador de chuva de aplicação intermitente, provido com bico do mesmo modelo.

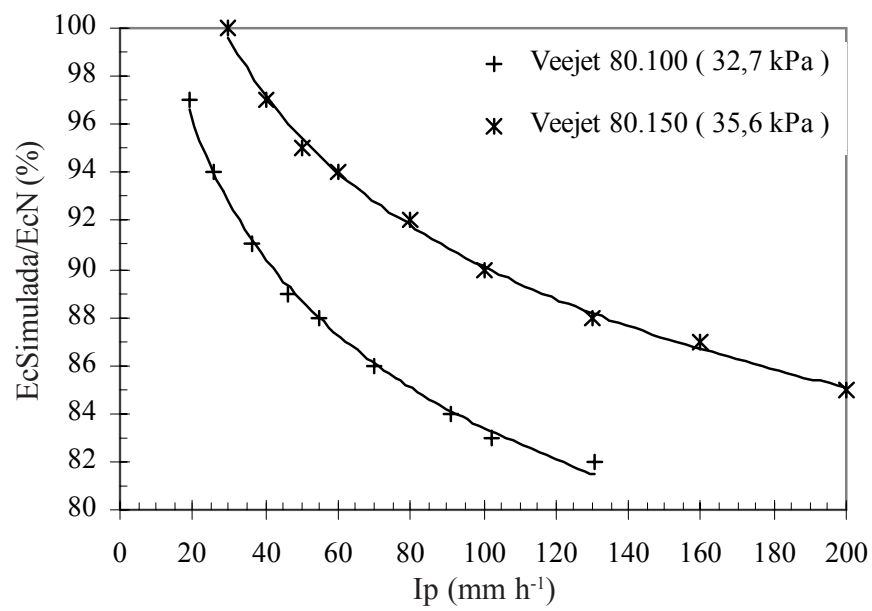

Figura 11. Relação entre energias em função da intensidade de precipitação

\section{CONCLUSÕES}

Considerando-se os testes realizados com o equipamento e os resultados obtidos, pode-se concluir que:

1. O infiltrômetro desenvolvido possibilita a determinação do escoamento superficial numa parcela experimental de $0,70 \mathrm{~m}^{2}$, com a utilização de dois bicos Veejet 80.100 ou 80.150, posicionados paralelamente a $400 \mathrm{~mm}$.

2. Os valores dos diâmetros médios das gotas obtidos, utilizando-se os bicos Veejet 80.100 e 80.150 , variaram de 1,8 a 3,0 mm, conforme a pressão de serviço.

3. O infiltrômetro, quando equipado com bicos Veejet 80.100, produz gotas com diâmetro médio e velocidade de impacto no solo semelhante às gotas de chuva natural para intensidades de precipitação de até $40 \mathrm{~mm} \mathrm{~h}^{-1} \mathrm{e}$, para intensidade de precipitação superior a $40 \mathrm{~mm} \mathrm{~h}^{-1}$ deve-se utilizar o bico Veejet 80.150 .

4. O equipamento desenvolvido permite aplicar-se intensidades de precipitação entre 19 e $308 \mathrm{~mm} \mathrm{~h}^{-1}$ de forma não intermitente, com valores de coeficiente de uniformidade de Christiansen variando entre 82 e $87 \%$

5. A relação entre a energia cinética da chuva produzida pelo infiltrômetro e a energia cinética da chuva natural, correspondeu a valores acima de $90 \%$ para intensidades de precipitação até $40 \mathrm{~mm} \mathrm{~h}^{-1}$ obtidas com bicos Veejet 80.100 , na pressão de $32,7 \mathrm{kPa}$, e até $100 \mathrm{~mm} \mathrm{~h}^{-1}$ com bicos Veejet 80.150 , na pressão de $35,6 \mathrm{kPa}$.

\section{LITERATURA CITADA}

Alves Sobrinho, T. Desenvolvimento de um infiltrômetro de aspersão portátil. Viçosa: UFV, 1997. 85p. Tese Doutorado 
Bajracharya, R.M.; Elliot, W.J.; Lal, R. Interrill erodibility of some Ohio soils based on field rainfall simulation. Soil Science Society of America Journal, Madison, v.56, n.1, p.276-272, 1992.

Brito, L.T.L.; Loureiro, B.T.; Deniculi, W.; Soares, J.M. Influência do método na determinação da velocidade de infiltração. Revista Brasileira de Ciência do Solo, Campinas, v.20, n.4, p.503-507, 1996.

Christiansen, J.P. Irrigation by sprinkling. Berkeley: University of California, Agricultural Experiment Station, 1942. 124p. Bulletin n. 670

Eigel, J.D.; Moore, I.D. A simplified technique for measuring raindrop size and distribution. Transactions of the ASAE, St. Joseph, v.26, n.4, p.1079-1084, 1983.

Ghidey, F.; Alberts, E.E. Interrill erodibility affected by cropping systems and initial soil water content. Transactions of the ASAE, St. Joseph, v.37, n.6, p.1809-1815, 1994.

Laws, J.O.; Parsons, D.A. The relation of rain drop size to intensity. Transaction, American Geophysical Union, Washington, v.24, p.452-459, 1943.

Li, J.; Kawano, H. Simulating water-drop movement from noncircular sprinkler nozzles. Journal of Irrigation and Drainage Engineering, New York, v.121, n.2, p.152-158, 1995.

Meyer, L.D.; Harmon, W.C. Multiple intensity rainfall simulator for erosion research on row sideslopes. Transactions of the ASAE, St. Joseph, v.22, n.1, p.100-103, 1979.

Meyer, L.D.; Mccune, D.L. Rainfall simulator for runoff plots. Agricultural Engineering, St. Joseph, v.39, n.1, p.644-648, 1958.

Morin, J.; Goldberg, D.; Seginer, I. A rainfall simulator with a rotating disk. Transacions of the ASAE, St. Joseph, v.10, p.74-79, 1967.
Pinto, N.L.; Holtz, A.C.T.; Martins, J.A. Hidrologia básica. 1.ed. São Paulo: Edgard Blücher, 1976. 279p.

Shelton, C.H.; von Bernuth, R.D.; Rajbhandari, S.P. A continuous application rainfall simulator. Transactions of the ASAE, St. Joseph, v.28, n.4, p.1115-1119, 1985.

Sidiras, N.; Roth, C.H. Infiltration measurements with double ring infiltrometers and a rainfall simulator under different surface conditions on an oxisol. Soil \& Tillage Research, Amsterdam, v.9, n.2, p.161-168, 1987.

Silveira, A.L.; Chevallier, P. Primeiros resultados sobre infiltração em solo cultivado usando-se simulação de chuvas (Bacia do Rio Potiribu, RS). In: Simpósio Brasileiro de Recursos Hídricos, 9, 1991, Rio de Janeiro. Anais... Rio de Janeiro: ABRH, 1991.p.213-221.

Smith, R.E. Approximations for vertical infiltration rate patterns. Transactions of the ASAE, St. Joseph, v.19, n.3, p.505-509, 1976.

Stillmunkes, R.T.; James, L.G. Impact energy of water droplets from irrigation sprinklers. Transactions of the ASAE, St. Joseph, v.25, n.1, p.130-133, 1982.

Tossell, R.W.; Dickinson, W.T.; Rudra, R.P.; Wall, G.J. A portable rainfall simulator. Canadian Agricultural Engineering, Guelph, v.29, n.2, p.155-162, 1987.

Tossell, R.W.; Wall, G.J.; Rudra, R.P.; Groenevelt, P.H. The Guelph rainfall simulator. II. A comparison of natural and simulated rainfall characteristics. Canadian Agricultural Engineering, Guelph, v.32, n.2, p. 215-223, 1990.

Wischmeier, W.H.; Smith, D.D. Rainfall energy and its relationship to soil loss. Transaction of American Geophysical Union, Washington, v.39, p.285-291, 1958. 